\title{
KEPEMIMPINAN PEMBELAJARAN KEPALA SEKOLAH DALAM MENINGKATKAN HASIL BELAJAR SISWA
}

\author{
Ahmad Wahyudi ${ }^{(1)}$, Sabar Narimo ${ }^{(2)}$, Wafroturohmah ${ }^{(3)}$ \\ Universitas Muhammadiyah Surakarta
}

DOI: 10.23917/varidika.v31 vi2i.10218

Submission
Track:
Received:
5 August 2019
Final Revision:
5 November 2019
Available online:
27 December 2019
Corresponding
Author:
Name \& E-mail Address
Ahmad Wahyudi ${ }^{(1)}$, Sabar
Narimo ${ }^{(2)}$, Wafroturohmah
wahyudiahmad96@ yahoo.com

\section{ABSTRACT}

This study has two objectives, namely to describe the implementation of learning leadership by principals in improving student learning outcomes. This is a qualitative research that produces descriptive data in the form of written or oral words from people and observable behavior. This research applied interview, observation and documentation in collecting the data. For analyzing the data, this research used a nonstatistic method, namely descriptive data analysis. It means that the data obtained through research on the implementation of learning leadership by principals and is reported as it is. Then, the data were analyzed descriptively to get an overview of the facts. Based on the results of research conducted in SMK Pelita Bangsa Sumberlawang, it can be concluded that the principal is the most important element in improving the quality of education. To be able to improve the quality of education, principals must conduct good learning leadership. The implementation of learning leadership in SMK Pelita Bangsa Sumberlawang in terms of the learning leadership model expressed by Hallinger and Murphy is divided into three dimensions, namely through the formulation of school missions, management of good learning and creating a conducive school climate. These three dimensions are then specified into eleven descriptors.

Keywords: Leadership, Learning, Principal. 


\section{PENDAHULUAN}

Pendidikan merupakan bagian penting dari proses pembangunan nasional yang ikut menentukan pertumbuhan ekonomi suatu negara. Pendidikan juga merupakan investasi dalam pengembangan sumber daya manusia, dimana pentingnya peningkatan dan pengembangan sumber daya manusia secara berkelanjutan merupakan salah satu kebijakan dalam meningkatkan mutu pendidikan. Salah satu isu penting dalam penyelengaraan pendidikan di Indonesia adalah mencari cara meningkatkan mutu pendidikan di tengah perubahan jaman yang bergerak sangat cepat saat ini. Berdasarkan Programme for International Study Assessment (PISA) pada tahun 2015 menempatkan Indonesia sebagai salah satu Negara dengan peringkat terendah dalam pencapaian mutu pendidikan. Dari 72 negara yang dilakukan penilaian, untuk kemampuan bidang matematika Indonesia menempati peringkat 65 dari 72 negara, bidang science menempati peringkat 63 dari 72 negara membaca menempati nomor 66 dari 72 negara. Hal ini dapat dilihat dari peringkat skor yang dicapai pada kemampuan membaca, matematika dan sains pada pelajar yang berusia 15 tahun.

Salah satu komponen yang sangat menentukan dalam proses pembelajaran pendidikan di sekolah adalah guru. Begitu pentingnya peran dan tanggung jawab guru, UU No. 14/2005 tentang Guru dan Dosen menyebutkan guru sebagai agen pembelajaran (learning agent) yang harus menjadi fasilitator, motivator, pemacu, perekayasa pembelajaran, dan pemberi inspirasi belajar bagi peserta didik. Selain itu guru juga memiliki tugas utama mendidik, mengajar, membimbing, mengarahkan, melatih, menilai, dan mengevaluasi peserta didik pada pendidikan anak usia dini jalur pendidikan formal, pendidikan dasar, dan pendidikan menengah.Dengan demikian maka guru mempunyai kedudukan dan peran yang penting dan strategis dalam rangka membentuk kepribadian bangsa melalui pengembangan potensi peserta didik dan nilai-nilai yang diinginkan. Salah satu tugas yang harus dilaksanakan oleh guru di sekolah adalah memberikan pelayanan kepada para siswa agar mereka menjadi siswa atau anak didik yang selaras dengan tujuan sekolah.

Pada kenyataannya harapan belum sesuai dengan kenyataannya. Berdasarkan hasil penelitian Badan penelitian dan pengembanganDinas pendidikan Nasional tahun 2006, menyatakanbahwa rendahnya kualitas pendidikan kita disebabkan oleh banyak faktor, dan salah satu faktor yang memberikan kontribusi besar adalah faktor Guru.Penelitian yang dilakukan oleh UNESCO melalui General Education Monitoring (GEM)Report tahun 2016 menempatkan pendidikan di Indonesia pada posisi ke 10 dari 14 negara berkembang. Penilaian pada segi kualitas guru menempatkan Indonesia pada peringkat ke 14 dari 14 negara berkembang atau berada pada posisi paling rendah.

Hal inilah yang menjadi tantangan bangsa Indonesia untuk dapat meningkatkan kualitas guru di sekolah. Bagaimana empat kompetensi guru yang meliputi kompetensi profesional, pedagogik, kepribadian dan sosial harus ditingkatkan. Dua kompetensi mutlak dilakukan pengembangan diri yaitu kompetensi profesional dan paedagogik. Kompetensi profesional diperlukan untuk meningkatkan kemampuan guru dalam konten pembelajaran dan kompetensi pedagogik diperlukan untuk meningkatkan kemampuan guru ketika mengajar, membuat perencanaan, memberikan penilaian, mendesain metode pembelajaran, manajamen kelas dan lainnya. Untuk dapat meningkatkan kualitas guru dalam meningkatkan kompetensinya, selain didalam diri guru itu sendiri kepala sekolah juga memiliki peran yang sangat penting.

Priansa (2014:49) mengemukakan bahwa kepala sekolah didefenisikan sebagai tenanga fungsional guru yang diberi tugas untuk memimpin sekolah tempat diselenggarakannya proses belajar mengajar, atau tempat dimana terjadinya interaksi antara guru yang memberikan pelajaran dan peserta didik yang menerima pelajaran.Tugas kepala 
sekolah salah satunya adalah kepemimpinan pembelajaran atau instructional leadership.Pengertian Kepemimpinan Pembelajaran menurut Eggen \& Kauchak (2004) adalah tindakan yang dilakukan (Kepala sekolah) untuk mengembangkan lingkungan kerja yang produktif dan memuaskan bagi guru pada akhirya mampu menciptakan kondisi belajar siswa semakin membaik.Kepemimpinan pembelajaran menurut Bush dan Glover (2013) adalah kepemimpinan yang menekankan pada komponen-komponen yang terkait erat dengan pembelajaran, meliputi kurikulum, proses belajar mengajar, penilaian, pengembangan guru, layanan prima dalam pembelajaran, dan pembangunan komunitas belajar di sekolah.

Tujuan utama kepemimpinan pembelajaran adalah memberikan layanan prima kepada semua siswa agar mereka mampu mengembangkan potensi, bakat, minat dan kebutuhannya. Selain itu juga untuk memfasilitasi pembelajaran agar siswa prestasi belajar meningkat, kepuasan belajar semakin tinggi, motivasi belajar semakin tinggi, keingintahuan terwujudkan, kreativitas terpenuhi, inovasi terealisir, jiwa kewirausahaan terbentuk, dan kesadaran untuk belajar sepanjang hayat karena ilmu pengetahuan dan teknologi serta seni berkembang pesat dan tumbuh dengan baik.

Dari uraian diatas, maka bagaimanakah peran kepala sekolah sebagai pemimpin pembelajaran dalam meningkatkan hasil belajar siswa di SMK Pelita Bangsa Sumberlawang Sragen? Penelitian ini memiliki tujuan yaitu mendeskripsikan pelaksanaan kepemimpinan pembelajaran kepala sekolah dalam meningkatkan hasil belajar siswa.

\section{METODE}

Penelitian ini merupakan penelitian kualitatif yaitu penelitian yang menghasilkan data deskriptif berupa kata-kata tertulis atau lisan dari orang-orang dan perilaku yang dapat diamati. Penelitian ini dilakukan di SMK Pelita Bangsa Sumberlawang, jalan Proyek Kedungombo km. 1, Ngandul, Sumberlawang, Kabupaten Sragen yang dilaksanakan mulai bulan Maret sampai dengan April 2019.

Teknik pengumpulan data menggunakan wawancara, observasi, dan dokumentasi. Teknik analisis data yang digunakan dalam penelitian ini adalah metode nonstatistik yaitu analisis data deskriptif artinya dari data yang diperoleh melalui penelitian tentang pelaksanaan kepemimpinan pembelajaran oleh kepala sekolah dilaporkan sesuai dengan keadaan kemudian dianalisis secara deskriptif untuk mendapatkan gambaran mengenai fakta yang ada. Langkahlangkah penyajian data melalui (1) reduksi data, (2) penyajian atau display data dan (3) pengambilan kesimpulan.

\section{HASIL DAN PEMBAHASAN}

\section{a. Pelaksanaan Kepemimpinan Pembelajaran Oleh Kepala Sekolah}

Berdasarkan hasil temuan pada saat melaksanakan penelitian kepemimpinan pembelajaran oleh kepala sekolah di SMK Pelita Bangsa Sumberlawang menunjukan bahwa kepala sekolah memiliki peran yang sangat penting dalam meningkatkan kualitas pendidikan di sekolah. Kepala Sekolah dituntut untuk mampu memimpin sekaligus mengorganisir dan mengelola pelaksanaan program belajar mengajar yang diselenggarakan di sekolah yang dipimpinnya. Kepala Sekolah harus mampu menjadi supervisor tim yang terdiri dari guru, staf, dan siswa dalam mewujudkan proses belajar mengajar yang efektif dan efisien sehingga tercapai produktifitas belajar yang pada akhirnya dapat meningkatkan mutu pendidikan. 
Kepala sekolah juga mempunyai tanggung jawab yang besar dalam mengelola manajemen sekolah yang terkait langsung dengan proses pembelajaran. Hal ini sesuai dengan pendapat Mulyasa (2013:24) yang menyampaikan bahwa kepala sekolah adalah komponen yang paling berperan dalam meningkatkan kualitas pendidikan. Didukung juga pendapat dari Ermita (2010) menyatakan bahwa kepala sekolah adalah salah satu komponen yang ikut berperan dalam pengelolaan lembaga pendidikan. Untuk dapat mencapai tujuan pendidikan dengan maksimal, tergantung pada keberhasilan dalam menyelenggarakan pendidikan dan pembelajaran pada setiap jenjang satuan pendidikan

Untuk dapat meningkatkan kualitas pendidikan maka kepala sekolah harus memiliki visi, misi, dan strategi manajemen pendidikan secara utuh dan berorientasi pada mutu pendidikan. Kepala sekolah diharapkan dapat menciptakan suasana kerja yang harmonis dan menciptakan iklim kerja serta budaya sekolah yang dapat memotivasi para guru untuk meningkatkan produktifitas dan efektifitas kerjanya dalam upaya mencapai tujuan pendidikan. Untuk dapat meningkatkan hasil belajar siswa, maka proses pembelajaran harus menjadi focus perhatian kepala sekolah. Pelaksanaan kepemimpinan pembelajaran kepala sekolah di SMK Pelita Bangsa Sumberlawang dalam upaya untuk meningkatkan hasil belajar siswa ditinjau berdasarkan model kepemimpinan pembelajaran yang di sampaikan oleh Hallinger dan Murphy (1985 adalah sebagai berikut:

\section{1) Merumuskan Misi}

Pada dimensi ini terdapat 2 deskriptor yaitu merumuskan tujuan sekolah dan mengkomunikasikan tujuan sekolah. Visi, misi dan tujuan sekolah SMK Pelita Bangsa Sumberlawang di rumuskan dan ditetapkan oleh Yayasan Pelita Bangsa. Kepala sekolah dan seluruh warga sekolah hanya sebagai pelaksana saja. Oleh karena itu kepala sekolah harus mampu merumuskan program kerja bersama dengan warga sekolah untuk mencapai tujuan sekolah. Setelah program kerja disusun selanjutnya mengkomunikasikan dengan seluruh warga sekolah dan stakeholder yang ada di sekolah. Seluruh program yang di susun oleh kepala sekolah harus berorientasi pada peningkatan hasil belajar siswa untuk dapat meningkatkan kualitas pendidikan di sekolah dan pencapaian tujuan sekolah.

Temuan ini sesuai dengan penelitian tentang kemampuan kepala sekolah terkait kompetensi administrasi dilakukan oleh Adegbemile yang berjudul Principal's Competency Needs For Effective Schools Administration In Nigeriadi tingkat sekolah menengah di South Geo Barat, Nigeria. Hasil penelitian menunjukkam bahwa keterampilan kepemimpinan instruksional yang dibutuhkan oleh kepala sekolah untuk administrasi sekolah yang efektif mencakup antara lain: (1) kepala sekolah bekerjasama dengan guru untuk menentukan tujuan Sekolah, (2) penyediakan fasilitas, (3) mengawasi rencana pelajaran, (4) kegiatan belajar mengajar, (5) evaluasi rencana dan pelaksanaan kurikulum.

Penelitian lain dilaksanakan oleh Prytula, Noonan, dan Hellsten yang berjudul "Toward Instructional Leadership: Principals' Perceptions of Large Scale Assessment in Schools". Penelitian ini mengkaji tentang persepsi kepala sekolah terhadap reformasi pengukuran kinerja kepala sekolah dan bagaimana pengukuran tersebut mempengaruhi peran mereka sebagai kepala sekolah. Hasil penelitian menunjukkan bahwa reformasi pengukuran kinerja kepala sekolah berpengaruh positif terhadap kepemimpinan pembelajaran yang mencakup penetapan tujuan sekolah, peningkatan pelaksanaan pembelajaran, perubahan pengukuran terhadap pembelajaran siswa. 
Dari hasil penelitian dan temuan di lapangan menerangkan bahwa penetapan tujuan sekolah penting dilaksanakan untuk memberikan arah dan tujuan sebuah proses pembelajaran di sekolah. Dalam menentukan sebuah tujuan sekolah tentu saja harus mempertimbangkan hal-hal yang ada di sekolah baik situasi maupun kondisi penunjang keberhasilan. Untuk mencapai sebuah keberhasilan tujuan sekolah, maka diperlukan sebuah target sebagai tolok ukur. Salah satunya adalah dengan menggunkan metode SMART yaitu specific, measurable, achievable, realistic dan time bound. Maksudnya bahwa target tujuan sekolah yang dibuat harus spesifik/focus, terukur, dapat di capai, menyesuaikan dengan situasi dan kondisi sekolah dan memiliki batas waktu pencapaian. Dengan demikian maka tujuan sekolah dapat lebih mudah di capai. Tujuan sekolah paling utama adalah hasil belajar siswa dapat mencapai hasil yang maksimal yang akhirnya berdampak pada kualitas pendidikan di sekolah.

\section{2) Mengelola Program Pembelajaran}

Pada dimensi ini terdapat tiga descriptor yaitu mensupervisi dan mengevaluasi pembelajaran, mengkoordinasikan kurikulum dan memonitor kemajuan pembelajaran siswa. Dimensi yang kedua pengelolaan program pembelajaran adalah tahapan proses utama dalam kegiatan pembelajaran di sekolah. Baik atau tidaknya kualitas pendidikan di sekolah sangat tergantung dari proses belajar mengajar di sekolah. Oleh karena itu kepala sekolah dalam perannya sebagai pemimpin pembelajaran perlu melakukan supervisi dan evaluasi pembelajaran. Kepala sekolah SMK Pelita Bangsa Sumberlawang juga melaksanakan supervisi pembelajaran secara periodic pada semua guru setiap satu tahun sekali pada awal tahun pelajaran. Hal ini sebagai upaya untuk membantu dan mengembangkan profesionalitas guru, dengan berorientasi pada teknik individu, kelompok, kunjungan kelas. Supervisi yang dilakukan bertujuan untuk meningkatkan proses kegiatan pembelajaran, sehingga seluruh aktivitas organisasi bermuara pada pencapaian efisiensi dan efektivitas pembelajaran. Dengan proses pembelajaran yang berjalan dengan efektif dan efisien, maka dapat meningkatkan hasil belajar siswa serta dapat meningkatkan kualitas pendidikan di sekolah.

Hal tersebut sesuai dengan penelitian Kotirde \& Yunos (2014) dalam penelitiaannya berjudul "The Processes of Supervision in Seconday Schools Educational System in Nigeria" bahwa proses supervisi sekolah menengah di Nigeria mencakup dua tahap yakni supervisi kepala sekolah dan supervisi guru. Setiap tahap berfokus pada pencapian hasil (output) supervisi masing-masing tahap. Output dari supervisi kepala sekolah adalah pada pencapaian frekuensi dan efektifitas dari aturan, nilai, karakter dan persaingan gender di sekolah. Sedangkan output dari supervisi guru adalah eksplorasi peran guru, partisipasi siswa, motivasi dan evaluasi pembelajaran.

Sidhu, G Kaur dan Fook, Chan Yuen (2010) dalam penelitiannya yang berjudul "Formative Supervision of Teaching and Learning: Issues and Concerns for the School Head" menjelaskan tentang peran kepala sekolah scbagai supervisi adalah untuk meningkatkan kualitas guru. Penelitian ini menyoroti mengenai pengetahuan, pemahaman dan praktek kepala sekolah dasar sebagai pengawas formatif dalam penelitian ditemukan bahwa kepala sekolah memiliki pemahaman terbatas dalam pelaksanaan supervisi. 
Penelitian lain dilakukan oleh Suryantini yang berjudul Peningkatan kompetensi supervisi kepala sekolah melalui supervisi kelompok di sekolah dasartentang kemampuan supervisi dengan fokus pada proses pelaksanaan supervisi kelompok guna meningkatkan kompetensi supervisi bagi Kepala sekolah. Berdasarkan penelitian tersebut hasilnya dapat di simpulkan bahwa: (1) proses pelaksanaan supervisi manajerial dilakukan melalui prosedur berbentuk siklus yang terdiri dari tiga tahap yaitu: tahap pertemuan pendahuluan, tahap pengamatan dan tahap pertemuan balikan; dan (2) penerapan supervisi manajerial metode kelompok efektif dalam meningkatkan kompetensi supervisi kepala sekolah. Hal ini ditunjukkan dengan hasil penilaian yang mengalami peningkatan pada setiap siklus tindakan yang dilakukan.

Faktor yang berkaitan dangan pelaksanaan supervisi pembelajaran mancakup proses penyusunan program, pendekatan yang digunakan dalam pelaksanaan supervisi, dan kagiatan tindak lanjutnya. Pelaksanaan supervisi di SMK Pelita Bangsa Sumberlawang sampai dengan saat ini yang sudah berjalan adalah tahap perencanaan dan tahap pelaksanaan supervisi pembelajaran. Sedangkan tahap pertemuan balikan/tindak lanjut belum dilaksanakan oleh guru maupun kepala sekolah. Hal inilah yang mengakibatkan palaksanaan supervisi hanya barsifat formalitas sekedar mamenuhi kewajiban saja.

Deskreptor yang kedua dari model kepemimipinan Hallinger dan Murphy adalah mengkoordinasikan kurikulum. Kurikulum merupakan panduan yang dijadikan guru sebagai kerangka acuan untuk mengembangkan proses pembelajaran. Seluruh aktivitas pembelajaran, mulai dari penyusunan rencana pembelajaran, pemilihan materi pembelajaran, menentukan pendekatan dan strategi/metode, memilih dan menentukan media pembelajaran, menentukan teknik evaluasi, kesemuanya harus berpedoman pada kurikulum.

Kurikulum harus disusun berdasarkan tuntutan perubahan jaman dan kemajuan masyarakat, sehingga kurikulum harus terus mengalami perubahan. Perubahan kurikulum adalah suatu keniscayaan,apabila kurikulum tidak mengalami penyesuaian dan perubahan sementara kehidupan sosial, teknolagi dan dimensi-dimensi kehidupan lainnya terus mengalami perubahan, maka dipastikan kurikulum tidak mampu memenuhi tuntutan perubahan. Dengan demikian mengakibatkan segala sesuatu yang diajarkan di sekolah tidak dapat mengikuti tuntutan perubahan yang terjadi pada dunia kerja.

Apa yang di uraikan di atas sesuai dengan penelitian Adegbemile dengan judul Principal's Competency Needs For Effective Schools Administration In Nigeria yang mengungkapkan bahwa kebutuhan kompetensi administrasi kepala sekolah untuk membangun sekolah yung efektif di tingkat sekolah menengah di South Geo Barat, Nigeriabahwa keteramapilan kepemimpinan instruksional yanq dibutuhkan oleh kepala sekolah untuk administrasi sekolah yung efektif mencakup antara lain: (1) kepala sekolah bekerja sama dengan guru untuk menentukan tujuan Sekolah, (2) penyediakan fasilitas, (3) mengawasi rencana pelajaran, (4) kegiatan belajar mengajar, (5) evaluasi rencana dan pelaksanaan kurikulum.

Hasil penelitian di SMK Pelita Bangsa Sumberlawang menunjukan bahwa dalam pembuatan kurikulum yang diterapkan bersifat statis dan kurang dapat mengikuti perubahan perkembangan jaman. Akibatnya output atau lulusan dari sekolah kurang dapat mengikuti kebutuhan pasar tenaga kerja yang ada di dunia industri. Hal inilah yang menyebabkan kenapa banyak sekali lulusan SMK Pelita 
Bangsa yang tidak terserap di dunia kerja sesuai dengan bidang keahlian yang di pelajari di sekolah.

Deskreptor yang ketiga yaitu memonitor kemajuan pembelajaran siswa. Monitoring adalah kegiatan yang dilaksanakan oleh kepala sekolah dalam rangka memantau kinerja guru. Pelaksanaan kegiatan monitoring yang dilakukan kepala sekolah yaitu dengan berjalan berkeliling disetiap teras kelas untuk memastikan bahwa bapak ibu guru telah melaksanakan kegiatan belajar mengajar di dalam kelas berjalan sesuai jadwal. Tidak jarang bapak kepala sekolah mengisi kelas bagi bapak ibu guru yang belum hadir. Kegiatan monitoring dilaksanakan secara rutin setiap pagi di sekolah agar proses pembelajaran dapat terlaksana dengan efektif dan efisien.

Pelaksanaan pemantauan di sekolah juga dilakukan dengan jalan mengumpulkan jurnal harian yang ada di kelas oleh wali kelas setiap seminggu sekali. Selanjutnya jurnal harian kelas direkap sebagai bahan laporan kepada kepala sekolah untuk dapat dilakukan tindak lanjut. Pengumpulan jurnal harian kelas adalah untuk mengetahui kedisiplinan guru dalam melaksanakan tugas mengajar, juga sebagai laporan proses kemajuan pembelajaran siswa. Dengan demikian maka kepala sekolah dapat mengetahui perkembangan pembelajaran siswa yang berada di dalam kelas, sehingga apabila terjadi permasalahan pembelajaran di dalam kelas segera diketahui dan terselesaikan oleh kepala sekolah. Kepala sekolah perlu melakukan monitoring terhadap pelaksanaan pembelajaran untuk mengetahui perkembangan proses dan kemajuan pembelajaran siswa. Dengan demikian pencapaian kompetensi sesuai dengan standar proses dan standar kompetensi lulusan dapat tercapai.

Hasil temuan dilokasi penelitian tersebut didukung oleh penelitian yang dilakukan oleh Adegbemile yang berjudul Principal's Competency Needs For Effective Schools Administration In Nigeria.Penelitian ini mengungkap kebutuhan kompetensi administrasi kepala sekolah untuk membangun sekolah yung efektif di tingkat sekolah menengah di South Geo Barat, Nigeriamenunjukkam bahwa keteramapilan kepemimpinan instruksional yang dibutuhkan oleh kepala sekolah untuk administrasi sekolah yung efektif mencakup antara lain: (1) kepala sekolah bekerja sama dengan guru untuk menentukan tujuan Sekolah, (2) penyediakan fasilitas, (3) mengawasi rencana pelajaran, (4) kegiatan belajar mengajar, (5) evaluasi rencana dan pelaksanaan kurikulum.

\section{3) Membangun Iklim Sekolah}

Pada dimensi ini terdiri dari enam descriptor yaitu mengkontrol alokasi waktu pembelajaran, mendorong pengembangan profesi, memfokuskan pencapaian visi, menyediakan insentif bagi guru, menetapkan standar akademi, dan menyediakan insentif bagi siswa. Berdasarkan hasil penelitian di SMK Pelita Bangsa Sumberlawang, enam descriptor diatas mampu membuat iklim sekolah menjadi kondusif. Dengan iklim sekolah yang aman, nyaman, dan menyenangkan (kondusif) mengakibatkan siswa lebih focus dalam belajar.

Hasil penelitian diatas di dukung penelitian yang dilakukan oleh Johnson, Uline, dan Perez (2011) dengan judul "Expert Noticing and Principals of HighPerforming Urban Schools". Penelitian ini bertujuan untuk mengkaji peranan kepemimpinan pembelajaran kepala sekolah dalam menunjang kemajuan sekolah di wilayah urban di Amerika Serikat. Hasil penelitian menunjukkan bahwa kepala sekolah memberikan perhatian yang tinggi terhadap hal-hal yang berkaitan dengan 
keterlibatan siswa dalam pembelajaran dan penciptaan iklim atau suasana di ruangan kelas. Kepala sekolah sangat memperhatikan tentang bagaimana guru dalam menciptakan suasana pembelajaran di kelas agar selalu kondusif.

Dengan demikian bisa disimpulkan bahwa untuk dapat melaksanakan proses pembelajaran yang efektif diperlukan iklim sekolah yang kondusif. Untuk dapat membangun iklim sekolah yang kondusif tersebut dapat dimulai dengan pengaturan waktu belajar siswa dalam setiap harinya, meningkatkan kompetensi atau profesionalitas guru dan penetapan standar akademik staf pengajar sesuai peraturan perundang-undangan yang ada. Hal lain yang dapat dilakuakn adalah menfocuskan dalam pencapaian visi sekolah, pemberian apresiasi berupa insentif bagi guru dan siswa yang berprestasi. Apabila semua descriptor tersebut dapat berjalan dengan baik, maka akan tercipta pembelajaran yang efektif. Buah dari pembelajaran yang efektif adalah meningkatnya hasil belajara siswa.

\section{PENUTUP}

Berdasarkan hasil penelitian yang dilakukan di SMK Pelita Bangsa Sumberlawang dapat diambil kesimpulan bahwa untuk dapat meningkatkan kualitas pendidikan maka kepala sekolah melaksanakan kepemimpinan pembelajaran.Pelaksanaan kepemimpinan pembelajaran di SMK Pelita Bangsa Sumberlawang ditinjau dari model kepemimpinan pembelajaran menurut Hallinger dan Murphy sudah berjalan dengan baik. Berdasarkan tiga dimensi yang digunakan sebagai indicator kepemimpinan pembelajaran hanya dimensi merumuskan misi yang tidak dilakukan oleh kepala sekolah. Visi, misi dan tujuan sekolah ditetapkan oleh Yayasan. Kepala sekolah dan jajarannya hanya sebagai pelaksana dengan menyusun program sekolah yang berorientasi terhadap tercapainya tujuan sekolah. Pengelolaan pembelajaran dilaksanakan dengan melakukan supervisi dan evaluasi pembelajaran, mengkoordinasikan kurikulum berdasarkan tuntutan perubahan dan kemajuan masyarakat, serta memonitor kemajuan pembelajaran siswa. Kepala sekolah harus mampu membangun iklim sekolah yang kondusif. Upaya membangun iklim sekolah yang kondusif dilakukan oleh kepala sekolah dengan caramengkontrol alokasi waktu pembelajaran, mendorong pengembangan profesi guru, memfokuskan pencapaian visi sekolah, menyediakan insentif bagi guru yang berprestasi, menetapkan standar akademi sesuai peraturan perundang-undangan yang ada bagi guru, dan memberikan insentif bagi siswa berprestasi.

\section{DAFTAR PUSTAKA}

Adegbemile, Oluwadare, 2011. Principal's Competency Needs for Effective Schools Administration in Nigeria,Journal of Education and Practice. www.iiste.org. ISSN: 2222-1735 (Paper) ISSN 2222-288X (Online) Vol 2 no 4.

Darno, 2013. Kepemimpinan Kepala Sekolah Dalam Meningkatkan Mutu Sekolah MI Tarbiyatul Athfal 03 Pengarasan Kecamatan Bantar Kawung Kabupaten Brebes Tahun Pelajaran 2011/2012. Tesis. Semarang: Program Pasca Sarjana Universitas Negeri Semarang

Erna Widiyanti. 2018. Pengaruh Kepemimpinan Kepala Sekolah dan Budaya Sekolah Melalui Motivasi Terhadap Kinerja Guru Sekolah Menengah Pertama Kota Semarang. Tesis. Semarang: Program Pasca Sarjana Universitas Negeri Semarang

https://en.wikipedia.org/wiki/Programme_for_International_Student_Assessment tahun 2015 
https://www.vedcmalang.com/pppptkboemlg/index.php/menuutama/departemen-bangunan30/1352-b-wijanarko, diakses hari sabtu, 8 Juni 2019 pukul 11.30 WIB

Johnson, Joseph F., Jr., Cynthia L Uline, dan Lynne G.Perez. 2011. ”Expert Noticing and Principals of High-Performing Urban Schools". Journal for The Education of Student Placed at Risk Vol 1, 2011. PP: 1-33, http://www.proquest.umi.com di akses pada 12 September 2018

Keputusan Menteri Pendidikan Nasional Nomor. 162/U/2003 tentang Pedoman Penugasan Guru sebagai Kepala Sekolah

Kotirde, I.Y \& Yunos J.B. Md, 2014. "The Processes of Supervision in Seconday Schools Educational System in Nigeria". Procedia Sosial and Behavioral Sciences, Vol.204.2015: pp 259-264

Mulyasa. 2013. Menjadi Kepala Sekolah Profesional. Bandung. PT. remaja Rosdakarya

Peraturan Menteri Pendidikan Dan KebudayaanNomor 22Tahun 2016TentangStandar Proses Pendidikan Dasar Dan Menengah

Peraturan Menteri Pendidikan Nasional No 13 Tahun 2007 Tentang Standar Kepala Sekolah/Madrasah

Priansa, Doni Juni, 2014, Manajemen Supervisi dan Kepemimpinan Kepala Sekolah, Bandung: Alfabeta

Prytula, Michelle, Brian Noonan, dan Laurie Hellsten. 2013. "Toward Instructional Leadership: Principals' Perceptions of Large Scale Assessment in Schools".Canadian journal of Educational Administration and Policy, Issue \#140, March 12, 2013, pp: 130, http://www.proquest.umi.com di akses pada 13 September 2018

Sidhu, G Kaur dan Fook, Chan Yuen. 2010. "Formative Supervision of Teaching and Learning: Issues and Concerns for the School Head". European Journal of Scientific Research. Vol. 39 No. 4. Pg:589-605.

Suryantini, 2016. Peningkatan Kompetensi Supervisi Kepala Sekolah Melalui Supervisi Kelompok di Sekolah Dasar, Jurnal Managemen Pendidikan. ISSN: 1907-4034, Vol 11, No. 2, Januari 2016: PP 9-17.

Undang-Undang Nomor 14 Tahun 2005 Tentang Guru Dan Dosen 